\title{
A Description of the Uses of Metacognitive Self- regulation and Cognitive Strategy Used with Reading Comprehension
}

\author{
Intan Septia Latifa \\ Universitas Pendidikan Indonesia, Bandung, Indonesia \\ Intan.latifa22@yahoo.com
}

\begin{abstract}
The reform of curriculum in Indonesia to the 2013 curriculum influences the way teachers teach in the classroom in which in this case they are demanded to apply studentcentered teaching. In order to implement the student-centered teaching, two components of self regulated learning; metacognitive self-regulation and cognitive strategy used are involved. Regarding to see the effectiveness of these components, this study is objected to investigate the uses of metacognitive selfregulation and cognitive strategy with reading comprehension. It employs a qualitative research design. 30 senior high school students participated in this study. The data were obtained from self regulated reading task adapted from Maftoon \& Tasnimi (2014). The result revealed that both components of SRL gave a positive relation with students' reading comprehension where cognitive strategies used were mostly used by the students. The implication of the study offers a suggestion for the English teachers to utilize both components of SLR in their teaching in order to improve students' reading comprehension through the best possible instruction.
\end{abstract}

Keywords: cognitive strategy used, metacognitive self-regulation, reading comprehension, self-regulated learning.

\section{INTRODUCTION}

The implementation of the 2013 curriculum has changed the way teachers teach which is previously on teacher-centered learning to student-centered learning. Moreover, new standard now explicitly includes "students actively learn" stating that students have an obligation to actively participate in their educational experience proved by good learning outcomes. They also need to practice how to observe, ask question, and do association and communication (Ministry of Education and Culture, 2013). This standard requires students' involvement in class to prepare them for careers that demand lifelong learning skills due to the rapid changing of technologies and business paradigm. Therefore, what teachers can do is to convince students to take responsibility for their education. One way to achieve that is by encouraging active participation for learners to initiate and control their learning process along with supportive learning strategies (Loranger, 1994). Self-Regulated Learning (SRL) refers to this responsibility since students will aware about how to plan their study for pursuing their goals.

Self-Regulated Learning (SRL) is defined as a socialcognitive model that conceptualizes effective learning as a cyclical process of evaluating cognitive and motivational processes during academic task (Zimmerman, 1990). This cycle is represented in three stages: planning, performance

and self-evaluation. Pintrich (2004) states that self-regulated learners adjust with the cycle through the use of strategies. In self-regulated learning, there are some strategies involved, metacognitive self-regulation and cognitive strategy used. Metacognitive self-regulation helps students to plan, monitor and evaluate their study, while cognitive strategy used deals with how students control the use of strategies based on planning created in terms of rehearsal, elaboration and organization.

Some related studies have conducted to evaluate and ensure the effectiveness of SRL in several subject matters in language teaching. Zimmerman \& Martinez-Pons cited in Zimmerman (1990) conducted a quantitative study to develop a theory of SRL and the correlation with students' achievement. It reveals that the students' use of SRL strategies made a distinctive contribution to their academic achievement apart from their general ability (p. 9). In addition, it was also supported by the teachers' ratings, which loaded highly on SRL factors such as goal setting and planning, self-monitoring, self-evaluation, reviewing and giving self-consequences.

Learning from the issues and problem raised in the first place, therefore the study will investigate the uses of self-regulated learning (SRL) components: metacognitive self-regulation and cognitive strategy used with reading comprehension.

In addition, this research aims to observe how well self-regulated learning works for students' reading activities. It has also investigated whether two components of SRL (cognitive strategy used and metacognitive self-regulation) can assist students to improve their reading comprehension.

\section{THEORETICAL FRAMEWORK \\ 2.1 SELF-REGULATED LEARNING (SRL)}

Zimmerman (2002) claims that self-regulation is not a mental ability or an academic performance skill, but it is a direct process which enables students to transform their mental ability into academic skills. He also acknowledges that self-regulation refers to self-generated thoughts, feeling and behaviors that are oriented to attaining goals (p. 65). As a result, the students have enhanced their awareness of their own strengths and weaknesses since they set goals individually. At the same time, they also monitor their 
behavior, increase their self-satisfaction and motivation in order to improve their method of learning. The outcomes are they will success academically as well as they will have a positive attitude about the future.

The definition above has been formulated based on Zimmerman's (1990) finding when investigating the relationship between SRL and achievement. He claimed that when students become engaged, they take greater responsibility for their learning and their academic performance improves. Furthermore, he illustrates selfregulated learners as those who are aware when they possess a skill and when they do not. They also have high interest to search for information they need and being wishful to master it. When they face some obstacles in learning, they are able to find a way to succeed. This can be achieved if the learners apply three models of SRL: plan, practice and evaluate.

Forethought phase or planning phase leads learning in the first place which associates with learners' motivational beliefs. The second phase is the performance phase or practice which encourages students to apply numerous strategies to maximize their academic performance. In that phase, observation on different aspects of performance will be done by the learners. Finally, self reflection or evaluation leading to judgment about one's action. Since those phases are considered cyclical, one phase will influence the other phase (Zimmerman, 2002).

Other than those phases, self-regulated learners do particular activities purposing on maintaining and controlling their learning to pursue their academic planning. As what stated by Cho (2010), self-regulated learners are proactive and commonly employ some activities such as cognitive activities which focus on rehearsal, elaboration and organization. In addition, they also include metacognitive activities which deal with goal setting, self monitoring and self-evaluation. Then, they also cover the time and effort management, seeking help from others and structuring environment through recourse management activities.

Recent conceptualization of SRL focused on cognitive and metacognitive features. Lau \& Ho (2015) define those two terms by stating "cognition concerns the application of different cognitive strategies for learning, while metacognitive strategies are used to control and regulate cognition" ( $\mathrm{p}, 2)$. In implementing these two major components, self-regulated learners have to be creative and skillful in selecting the strategies which suite their task and apply it appropriately. In addition, Pinrich and De Groot (1990) specified metacognitive strategies for planning, monitoring and modifying student cognition. Moreover, cognitive strategies assist students to be accustomed to learn, remember and understand the material.

\subsection{SRL AND READING COMPREHENSION}

In relation to student reading activities, the utilizing of SRL is essential because it is a goal-directed behavior (extracting meaning from the text) that needs effort. SRL will assist the students to enrich their knowledge of the reading text through some stages, (1) students must engage with text to develop a specific goal, (2) associate text with their background knowledge, (3) make inferences within text, and (4) evaluate their reading performance to ascertain whether their performance is adequate (Cirino, Miciak, Gerst, Barnes, Vaugh, Child \& Warren, 2016: 2).

To accomplish those stages above, this study will use SRL strategies proposed by Zimmerman (1989: 327) in guiding students to control and organize their reading activities.

Table 1. SRL strategies

\begin{tabular}{|c|c|c|}
\hline Strategies & Categories & Definition \\
\hline $\begin{array}{l}\text { Organizing \& } \\
\text { transforming }\end{array}$ & $\begin{array}{l}\text { Metacognitive } \\
\text { strategy }\end{array}$ & $\begin{array}{l}\text { Statements } r \text { student- } \\
\text { initiated overt or covert } \\
\text { rearrangement } \\
\text { instructional materials to } \\
\text { improve learning. }\end{array}$ \\
\hline $\begin{array}{l}\text { Goal-setting \& } \\
\text { planning }\end{array}$ & $\begin{array}{l}\text { Metacognitive } \\
\text { strategy }\end{array}$ & $\begin{array}{l}\text { Statements } \\
\text { students' } \text { indicating } \\
\text { educting of } \\
\text { goal and planning for } \\
\text { sequencing, timing and } \\
\text { completing activities } \\
\text { related to those goals. }\end{array}$ \\
\hline $\begin{array}{l}\text { Keeping } \\
\text { record } \quad \& \\
\text { monitoring }\end{array}$ & $\begin{array}{l}\text { Metacognitive } \\
\text { strategy }\end{array}$ & $\begin{array}{l}\text { Statements indicating } \\
\text { student-initiated efforts to } \\
\text { record events or result. }\end{array}$ \\
\hline $\begin{array}{l}\text { Seeking } \\
\text { information }\end{array}$ & $\begin{array}{l}\text { Cognitive } \\
\text { strategy }\end{array}$ & $\begin{array}{l}\text { Statements indicating } \\
\text { student-initiated efforts to } \\
\text { secure further task } \\
\text { information } \\
\text { nonsocial sources when } \\
\text { undertaking an assignment. }\end{array}$ \\
\hline $\begin{array}{l}\text { Rehearsing \& } \\
\text { memorizing }\end{array}$ & $\begin{array}{l}\text { Cognitive } \\
\text { strategy }\end{array}$ & $\begin{array}{l}\text { Statements indicating } \\
\text { student-initiated efforts to } \\
\text { memorize the material by } \\
\text { overt or covert practice. }\end{array}$ \\
\hline $\begin{array}{l}\text { Reviewing } \\
\text { records }\end{array}$ & $\begin{array}{l}\text { Cognitive } \\
\text { strategy }\end{array}$ & $\begin{array}{l}\text { Statements indicating } \\
\text { student-initiated efforts to } \\
\text { reread notes, tests or } \\
\text { textbook to prepare for } \\
\text { class or further testing. }\end{array}$ \\
\hline $\begin{array}{l}\text { Self-evaluation } \\
\& \quad \text { Self- } \\
\text { consequating }\end{array}$ & $\begin{array}{l}\text { Metacognitive } \\
\text { strategy }\end{array}$ & $\begin{array}{l}\text { Self evaluation: statements } \\
\text { indicating student-initiated } \\
\text { evaluation of the quality or } \\
\text { progress of their work. } \\
\text { Self-consequating: } \\
\text { statement indicating } \\
\text { student arrangement or } \\
\text { imagination of rewards or } \\
\text { punishment for success or } \\
\text { failure. }\end{array}$ \\
\hline
\end{tabular}

As the general recognition, metacognitive strategies are utilized in numerous stages of the learning process. Zimmerman (2002) differentiated three stages, forethought stage, which involves the development of planning strategies including time allocation. The following stage is performance stage where learning takes place, in which monitoring 
strategies take a part to encourage students to repeatedly check the material. Then, it is ended by self-reflection where students evaluate the learning process and learning outcomes.

Furthermore, cognitive strategies are on a lower level than metacognitive strategies which mainly focus on specific tasks. Elaboration strategies are involved when dealing with prior knowledge and new material, rehearsal strategies assist to store the information and organization strategies will visualize the material to facilitate learning (Boer, DonkerBergstra \& Kostons, 2012).

There are a lot of interests showed by the researchers in SRL and reading comprehension. Housand \& Reis (2008) implemented the School wide Enrichment Model-Reading (SEM-R) to reading instruction to increase self-regulation. He discovered there were higher opportunities for SRL in SEM$\mathrm{R}$ including student choice in reading material, flexibility in classroom procedures and encouragement in engaging in complex tasks. Meanwhile, Maftoon \& Tasnimi (2014) found a significant effect of using SRL on reading comprehension in language program for ESP/EAP purposes in Iran. Fadlelmula \& Ozgeldi (2010) study focused on each phase in different models of SRL adopted from Pintrich. The result revealed that all the phases in the model were apparent in the participant's reading comprehension task. Ayatollahi, Rasekh \& Tavakoli (2012) investigated whether and how university students' belief (epistemological belief) about the nature of knowledge affected L2 academic reading ability directly and/or indirectly via self-regulated learning strategies. It found that epistemological beliefs had both direct and indirect effects on L2 academic reading ability via self-regulated learning strategies. It was also found metacognitive and resource management strategies influenced cognitive strategies which become the one influencing L2 academic reading ability.

\section{METHODS}

It is a qualitative research design aiming at exploring and understanding the issue (Maliek \& Hamied: 2016) and applied descriptive study as its framework viewing that everything is potential to provide a clue that reveals a more comprehensive understanding (Bogdan \& Biklen, 2006). The standard used in choosing participants and sites is whether they are "information rich" (Patton cited in Creswell, 2008: 214). Based on the argument, the researcher used "purposeful sampling" for this study. The participants of the study were 30 junior high school students (second grade) in one of the state schools in Bandung. The instrument utilized in this study was self-regulation reading task adapted from Maftoon \& Tasnimi (2014). The task consists of several stages based on the elements in both metacognitive self-regulation and cognitive strategy used. In collecting the data, 30 selfregulation reading task were distributed to second grade students who required to respond to eight strategies which divided into metacognitive self-regulation and cognitive strategy used. The data were analyzed using descriptive analysis based on the theory of self-regulated learning by Zimmerman (1998,2002).

\section{DISCUSSION}

4.1 HOW COGNITIVE STRATEGY USED AND METACOGNITIVE SELF-REGULATION RELATE TO STUDENTS' READING COMPREHENSION?

a. Metacognitive self-regulation

The result of self regulated reading task revealed that the majority of the students have a positive attitude to the use of metacognitive self-regulation, especially in goal setting and planning, keeping records \& monitoring, and selfevaluation \& self-consequating. However, in organizing and transforming the text, some students encountered some problems, especially in determining the main idea and supporting ideas of the text, but in the other case in terms of choosing the correct title or identify the number of paragraph, they can manage it well.

Making a plan and setting a goal in terms of how much time they spend in reading a text and answering several questions, assisted students to manage the effectiveness of their reading task. Three-forth of the students had completed their time based on the planning. So, it can be assumed that these strategies assisted them in maintaining their reading activities.

In keeping records and monitoring when dealing with difficult words in the text, in general, all students have known the ways to highlight the words. Besides three common ways such as annotating, underlying and rewriting those on the notebook, they usually enclose those with a circle, highlight those with a colored pen, make a mark or give a note on them. Those strategies help them to get the clue of what the text is about, in which the result is that they are able to draw an outline of the paragraph. The samples of the outlines are available in the following table:

Table. 2 Samples of outlines of the narrative text

Outline "Don't be so arrogant, because arrogant can make 1 you lose control and be fooled. People don't like an arrogant person, so be kind and don't angry easily".

Outline "Because the lion strength, the lion uses his 2 strength to bully and frighten the rabbit"

Dealing with self-evaluation \& self-consequating as a final stage, the students completed 5 questions. The result showed that more than $80 \%$ of the students declared that they got the text on the scale of $50 \%$ to $100 \%$, while the rest got $100 \%$ and only one student got the text under $50 \%$. Moreover, as a reward for their effort, they put themselves on the scale between 7 to 8,5 out of 10 in their reading comprehension, which are categorized in medium level.

In terms of improving their reading comprehension, the students made lists of the progress they should be accomplished, which are (1) enrich their vocabulary and improve their understanding of grammar, (2) be more accurate in reading the text by considering punctuation and speed of reading, and (3) do a lot of reading practice.

\section{b. Cognitive strategy used}

The cognitive strategy used emphasizes to assisting students to learn, remember and understand the material. In 
this case, students showed their positive attitude to the use of cognitive strategy used in completing the reading task. It had been discovered that, in seeking information, most students have applied four strategies offered in the reading task, such as guessing, consulting a dictionary, asking the friend and teacher when they found ambiguous words in the text with different purposes. Mostly, students are guessing when they can pick a suitable meaning for the word after adjusting it with the whole sentence or paragraph. Asking friends will be chosen when they are doubt with their own definition. Then they asked teachers or consulted a dictionary for a definite answer of the word.

Moreover, when dealing with rehearsing and memorizing, the students commonly used mental imagery, translation, synonyms and transferring to the note, as strategies. In addition, some strategies which considered helpful in rehearsing and memorizing are through some enjoyable activities such as watching movies with English subtitle, listening music with the lyrics and reading English books like comics or novels.

Finally, in reviewing the records or evaluation, students agreed that all steps of SRL help them to maintain their reading activities effectively. It is in line with the overall score they got on self-regulation reading task where nearly half of the students got the score of 80 , more than one-third of the students reached the highest score which is 100 and the rest received 60 .

\subsection{WHICH COMPONENT OF SRL BETWEEN METACOGNITIVE SELF-REGULATION AND COGNITIVE STRATEGY USED GIVES THE MOST IMPACT ON STUDENTS' READING COMPREHENSION?}

Metacognitive self-regulation and cognitive strategies used are the main components in SRL which run together. The cognitive strategy used refers to the different individual tactics that learners use to improve learning, while metacognitive self-regulation helps them to be self-aware and decisive in their learning. However, this idea did not seem to work in that way, since the students had less attention on the use of metacognitive self-regulation compared to cognitive strategy used. The result of self-regulation reading task revealed that students tended to ignore the process of organizing and transforming the text which is the first activity to be fulfilled in metacognitive self-regulation strategy. Some of them were also not used to do planning before doing the reading task. As a result, they had a problem in managing their time in completing the reading task.

While applying the cognitive strategies used; the students had more initiative, especially in rehearsing and memorizing. Some strategies, for instance through watching movies, listening song with lyrics, reading novels and so on and so forth. They also showed their positive attention on seeking the information of ambiguous words through some efforts, such as guessing, asking friends or teachers and consulting a dictionary.

\section{CONCLUSION}

From the discussions presented earlier, it can be concluded that both metacognitive self-regulation and cognitive strategies used gave a positive relation with students' reading comprehension. Both strategies assisted students to utilize individual tactics that learners use to improve learning and to increase their self-aware and decisive their learning. In addition, among metacognitive selfregulation and cognitive strategies used, the one which mostly used by the students is cognitive strategies used. The reasons might be referred to the substantial awareness and control of their cognitive activity while interacting with the text. It is hoped that this research provides implications for teachers and learners. The present study can help teachers of English to develop a clear understanding of SRL to be implemented in a pedagogical context. Taking the findings of the study into consideration, teachers would be able to understand the significance of metacognitive self-regulation as well as cognitive strategy used and consider this to be utilized in their teaching in order to improve students' reading comprehension through the best possible instructions.

\section{REFERENCES}

Ayatollahi, M. A, Rasekh, A. \& Tavakoli, M. (2012). Learner belief, self-regulated learning strategies and L2 academic reading comprehension: a structural equation modeling analysis. World Applied Sciences Journal, 17(1), 36-49.

Boer, H., Donker-Bergstra, A.S., \& Kostons, D. D. N. M. (2012). Effective Strategies for Self-Regulated Learning: A Meta-analysis. GION: Rijksuniversiteit Groningen.

Bogdan, R. \& Biklen, S. K. (2006). Qualitative Research for Education: An Introduction to Theories and Methods. USA Pearson Education, Inc.

Cirino, P. T., Miciak, J., Gerst, E., Barnes, M.A., Vaugh, S., Child, A., \& Huston-Warren, E. (2016). Executing function, self-regulated learning and reading comprehension: a training study. Journal of Learning Disabilities, 1-18.

Cho, M. H. (2010). The effects of design strategies for promoting students' self-regulated learning skills on students' self-regulation and achievement in an online learning environment. Retrieved March 12, 2016, from http://eric.ed.gov/ERICDocs/ data/ericdocs2sq1/content_storage_01/0000019b/80/1b la7/72.pdf

Creswell, J. W. (2008). Educational Research: Planning, Conductinga and Evaluating Quantitative and Qualitative Research. Third Edition. New Jersey: Pearson Education International.

Fadlelmula, F. K. \& Ozgeldi, M. (2010). How a learner selfregulates reading comprehension: a case study for graduate level reading. US-China Education Review, $7(10), 22-28$. 
Hausand, A. \& Reis, S. M. (2008). Self-regulated learning in reading: gifted pedagogy and instructional setting. Journal of Advanced Academic, 20(1), 108-136.

Lau, K, \& Ho, S. (2015). Reading performance and selfregulated learning of Hong Kong students: what we learnt from PISA 2009. Asia-Pasific Edu Res, 1-13. retrieved April 4, 2016, from http://www.fed.cuhk.hk/ hkpisa/output/files/Lau_Ho_ 2015 Springer.pdf

Loranger, A. L. (1994). The study of strategies of successful and unsuccessful high school students. Journal of Reading Behavior, 20, 28-36.

Maftoon, P. \& Tasnimi, M. (2014). Using self-regulated to enhance EFL learners' reading comprehension. Journal of Language Teaching and Research, 5(4), 844-855.

Malik, R. S., \& Hamied, F. A. (2016). Research Method. Bandung: UPI PRESS.

Ministry of Education and Culture. (2013). Kurikulum 2013: Kompetensi dasar.

Pinrich, P. R. (2004). A conceptual framework for assessing motivation and self-regulated learning in college students. Educational Psychology Review, 16(14), 385-407

Pinrich, P. R., \& De Groot, E. V. (1990). Motivational and self-regulated learning components of classroom academic performance. Journal of Educational Psychology, 2(1), 33-40.

Zimmerman, Barry J. (1989). A social cognitive view of selfregulated academic learning. Journal of Educational Psychology, 81(3), 329-339.

Zimmerman, B. J. (1990). Self-regulated learning and academic achievement: an overview. Educational Psychologist, 25(1), 3-17.

Zimmerman, B. J. (2002). Becoming a self-regulated learner: an overview. Theory into Practice, 41(2), 64-70 